Case

Report

\title{
A Case of an Aortic Abscess around the Elephant Trunk
}

\author{
Takeshiro Fujii, MD, Muneyasu Kawasaki, MD, Tomoyuki Katayanagi, MD, \\ Shinnosuke Okuma, MD, Hiroshi Masuhara, MD, Noritsugu Shiono, MD, \\ and Yoshinori Watanabe, MD
}

\begin{abstract}
A 52-year-old male patient with a history of total arch replacement using the elephant trunk technique for acute aortic dissection 4 years before visited our hospital with the chief complaint of persistent fever. Chest computed tomography (CT) suggested prosthetic vascular graft infection, which was treated surgically after chemotherapy. The first surgery consisted of debridement of an abscess around the vascular graft and in the aorta around the elephant trunk, and thoracic descending aorta replacement and vacuum-assisted closure (VAC) in view of the risk of bleeding from the peripheral region of the elephant trunk. One week later, omental filling was performed as the second step. This is a very rare case of aortic abscess around the elephant trunk that could successfully be managed by graft-conserving treatment.
\end{abstract}

Keywords: aortic abscess, elephant trunk, prosthetic vascular graft infection, vacuum-assisted closure, omental flap

\section{Introduction}

The incidence of prosthetic vascular graft infection in the thoracic aortic area is approximately $3 \% .^{1}$ In most cases, an abscess forms around the vascular prosthesis. Treatment included vascular graft replacement as an invasive procedure after removal of infected tissues and debridement. Based on the results of this treatment approach, a two-step method involving an omental filling procedure after vacuum-assisted closure (VAC), without vascular graft replacement, has provided favorable results at present.

Division of Cardiovascular Surgery, Department of Surgery, School of Medicine, Faculty of Medicine, Toho University, Tokyo, Japan

Received: May 8, 2015; Accepted: June 12, 2015

Corresponding author: Takeshiro Fujii, MD. Division of Cardiovascular Surgery, Department of Surgery, School of Medicine, Faculty of Medicine, Toho University, 6-11-1 Omorinishi, Ota-ku, Tokyo 143-8541, Japan

Email: fujiit@med.toho-u.ac.jp

(C)2015 The Editorial Committee of Annals of Thoracic and Cardiovascular Surgery. All rights reserved.
However, there are no other reports of prosthetic graft infection with abscess after elephant trunk replacement of the aorta. In such a case, treatment may be complicated. Here we report a case of late prosthetic vascular graft infection with graft site infection and aortic abscess formation around the elephant trunk 4 years after total arch replacement using the elephant trunk technique for acute aortic dissection, including the favorable results obtained in this case.

\section{Case Report}

A 52-year-old man, who had undergone total arch replacement using the elephant trunk technique for acute Stanford type A aortic dissection at our hospital at the age of 48 years, visited our hospital with general malaise, night sweats, and gluteal pain for 3 months and an occasional fever of $39^{\circ} \mathrm{C}$ for 1 month. He was admitted for detailed examinations.

Hematological findings on admission included C-reactive protein (CRP) of $4.7 \mathrm{mg} / \mathrm{dl}$, hemoglobin of $10.3 \mathrm{~g} / \mathrm{dl}$, white blood cell count of $7700 / \mu \mathrm{l}$, procalcitonin of $0.135 \mathrm{ng} / \mathrm{ml}$, and erythrocyte sedimentation rate of $55 \mathrm{~mm} / \mathrm{hr}$. Blood 
(A)

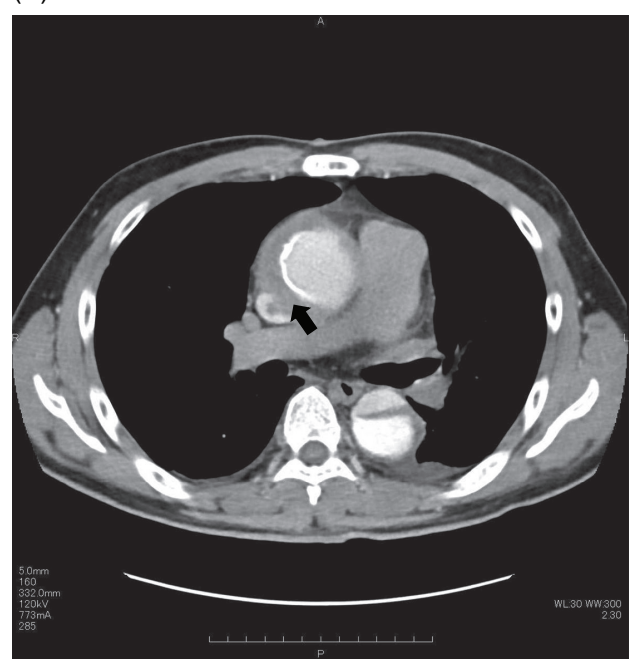

(B)

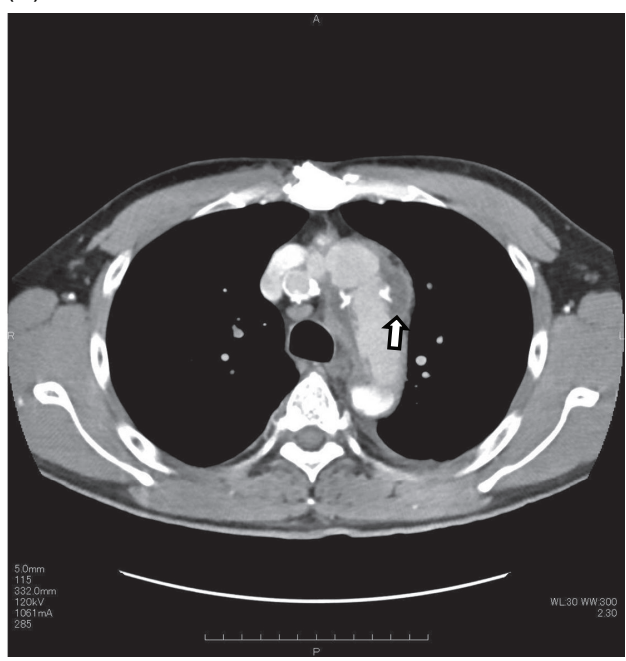

Fig. 1 Preoperative chest CT. (A) At the level of the ascending aorta: perigraft fluid with a density $<41$ Hounsfield Units $(\leftarrow)$. (B) At the level of the aortic arch: perigraft fluid with a density $<14$ Hounsfield Units $(\Leftarrow)$. CT: computed tomography

(A)

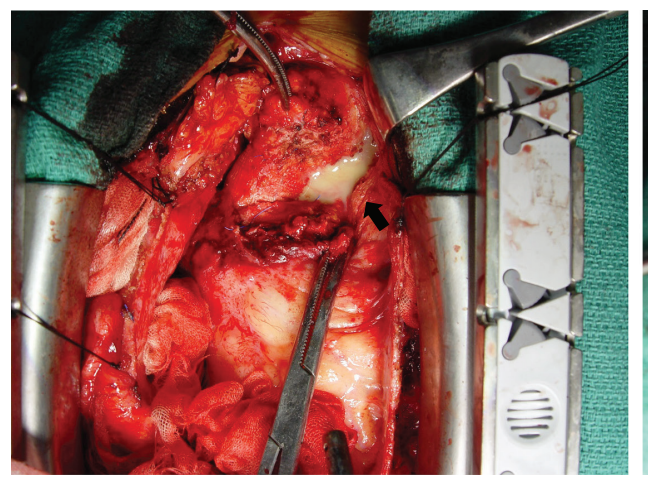

(B)

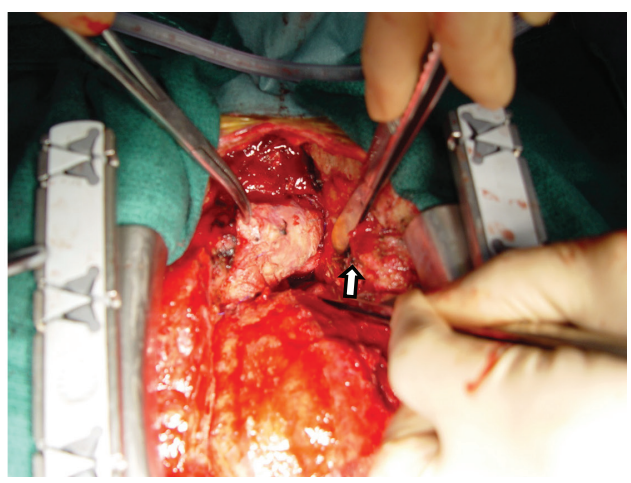

Fig. 2 Findings at the first surgery. (A) Pus drainage from the aortic abscess $(\longleftarrow$ ). (B) Elephant trunk exposed after pus drainage $(\Leftarrow)$.

bacterial culture was negative. Chest CT revealed a low density area around the vascular graft (Fig. 1), and Ga scintigraphy showed increased accumulation at the same site. Based on a strong suspicion of prosthetic vascular graft infection, the patient received chemotherapy with antibiotics for 1 month, followed by surgical procedures. The anterior mediastinum median was dissected with median sternotomy. Since an abscess was found around the vascular graft, lavage and debridement of infected tissues were performed. When dissection of the abscess cavity had advanced to the level of the aortic arch, the elephant trunk vascular graft was exposed (Fig. 2). At the time, the abscess cavity was found to involve the space between the aortic wall and the elephant trunk graft. The abscess was thus found to surround the vascular prosthesis in the anterior mediastinum and to involve the aorta bound by the aortic wall (Fig. 3). Due to the risk of bleeding from the peripheral region of the elephant trunk, the patient was immediately placed in the right lateral position. Using thoracotomy through the left forth intercostal space and partial extracorporeal circulation with blood delivered through the left femoral artery and drained from the left femoral vein, we performed vascular graft replacement of the region from the elephant trunk prosthesis to the thoracic descending aorta at the diaphragmatic level, and then closed the chest. VAC was performed on the debrided anterior mediastinum in preparation for the second step with an omental flap filling procedure. One week later, following gentian violet application to 


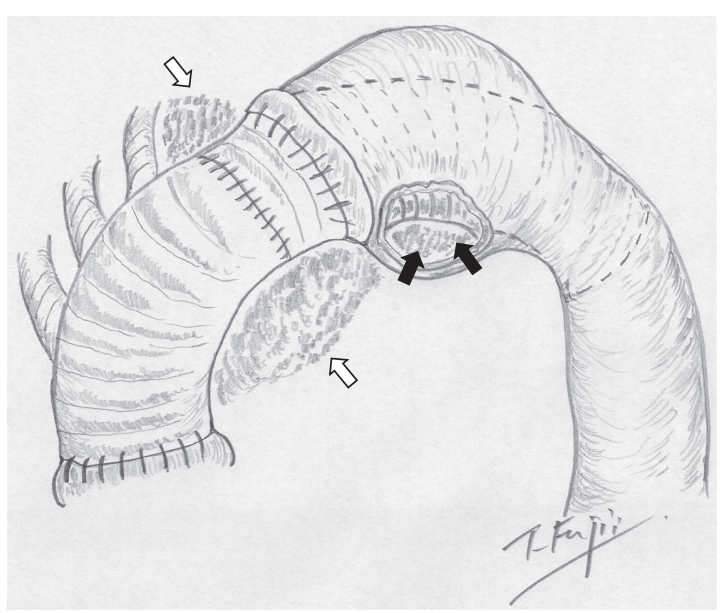

Fig. 3 Schema at the first surgery. Abscess around the vascular graft $(\Longleftrightarrow)$. Abscess cavity in a space between the aortic wall and the elephant trunk graft $(\longleftarrow)$.

the anterior mediastinum, an omental flap filling procedure was performed and the chest was closed. The patient showed favorable postoperative progress. His condition improved after 1-month chemotherapy, and he was discharged. Bacterial culture of pus and tissues collected during the surgery was negative. All surveillance culture samples collected perioperatively were also negative. As of 10 months postoperatively, there has been no recurrence of the infection.

\section{Discussion}

While most cases of prosthetic vascular graft infection are considered to be caused by surgical site infection (SSI), the cases are classified into two categories, early prosthetic graft infection (onset within less than 4 months postoperatively) and late prosthetic graft infection (onset from 4 months postoperatively and later). ${ }^{2}$ Early prosthetic graft infection often starts with sternal wound infection-related symptoms such as fever, cold sweats, chills, precordial pain, and purulent discharge from the wound within 30 days postoperatively; this is a typical case associated with SSI. Some of these early-onset cases, however, have only slight increases in white blood cell count and CRP, and no symptoms. ${ }^{1,3-6)}$ Late prosthetic graft infection may occur 20 years postoperatively or later; in these late-onset cases, SSI is unlikely to be involved in the mechanism of development. ${ }^{4)}$ Shiono et al. ${ }^{7)}$ studied the relationship between periodontal disease and infectious endocarditis and reported that oral pathogenic bacteria causing oral lesions were also detected from cardiac valve tissues, vegetation, and blood at a high frequency. This report suggests that an opportunity for bacteria to enter the blood, not limited to periodontal disease, can be a factor in the development of infectious disease. In a basic research study to investigate the pathology of prosthetic graft infection, an author immersed vascular grafts in Pseudomonas culture liquid and measured the bacterial content in saline in the vascular graft to assess the bacterial permeability. The author reported the possibility that bacteremia might induce infection around the vascular graft through bacterial invasion of the graft. ${ }^{8)}$ The mechanism of infection in our case is unlikely to be related to SSI in the light of the onset timing of 4 years postoperatively. In this case, since a persistent slight CRP increase almost normalized with oral antibiotic therapy continued for several months during the postoperative course of the first surgery, a localized latent SSI with weak pathogenic bacteria may have induced abscess formation and prosthetic vascular graft infection upon activation of the bacteria due to changes in the host.

It is important to identify infectious pathogens in cases of prosthetic graft infection. Culture of blood or tissue specimens collected from patients with prosthetic graft infection is negative in one third of the cases. ${ }^{3)}$ In our case, no bacteria were detected from culture of pus and tissue specimens collected intraoperatively. Gram-positive bacteria, especially Staphylococcus aureus, are the prevalent pathogens involved in approximately $75 \%$ of all cases. ${ }^{9)}$ Late-onset vascular PVGI are usually associated with less virulent organisms such as coagulase-negative Stapylococcus, Cirynebacterium, or Propionibacterium species. ${ }^{10)}$ It is expected that bacterial identification will be performed using metagenome analysis in the future. ${ }^{11)}$

For the treatment of prosthetic vascular graft infection in the thoracic aortic area, Coselli et al. ${ }^{1)}$ reported a composite of aortic graft reconstruction and omental filling procedures after re-thoracotomy and debridement in 1999, resulting in a high 1-year mortality rate of approximately $30 \%$. In 1984, Hargrove et al. ${ }^{12)}$ reported successful infection control by omental filling without removal of infected prosthetic grafts. The results of a similar approach reported by Coselli et al. ${ }^{1,3,13)}$ were favorable, as represented by an $88 \%$ early survival rate and no recurrence. Nakajima et al. ${ }^{14)}$ took the same approach using povidone iodine packing and reported both a $100 \%$ survival rate and a $100 \%$ recurrence prevention rate. These methods have been used until recent years for the treatment of prosthetic vascular graft infection. Since the report of Obdeijn et al. ${ }^{15)}$ in 1999, however, VAC therapy has been spreading rapidly. ${ }^{16)}$ It is applied to refractory mediastinitis as a less invasive treatment. VAC therapy applies stronger negative pressure than 
usual aspiration drainage but is highly safe. The therapy facilitates granulation and neovascularization without damaging tissues or the anastomosed site and efficiently removes slime produced by bacteria and degradation products. Based on these functions, the therapy is expected to increase the cure rate of mediastinitis and shorten the duration of treatment. Despite only a few reports on VAC therapy after thoracic aortic prosthetic replacement, its effectiveness after vascular prosthetic replacement has been reported. ${ }^{17,18)}$ While some authors reported one-step procedures of removal of infected and necrotic tissues, debridement, and filling procedure, followed by wound closure, ${ }^{19)}$ VAC therapy provides a more reliable approach with a reduction in bacterial load and multiple negative bacterial culture, followed by filling with omental or pedicled muscle flaps and wound closure. ${ }^{20)}$ In the present case, omental filling procedure was performed after negative bacterial culture of specimens obtained during the first surgery was confirmed. This two-step approach produced favorable results.

\section{Conclusion}

We experienced a possibly very rare case of late prosthetic vascular graft infection with aortic abscess formation around the elephant trunk. Following removal of infected tissues, thoracic descending aorta replacement, and VAC therapy, an omental filling procedure was performed as the second step. This two-step approach successfully achieved infection control.

\section{Disclosure Statement}

All authors have no conflict of interest to disclose with respect to the present case report.

\section{References}

1) Coselli JS, Crawford ES, Williams TW, et al. Treatment of postoperative infection of ascending aorta and transverse aortic arch, including use of viable omentum and muscle flaps. Ann Thorac Surg 1990; 50: 868-81.

2) Tossios P, Karatzopoulos A, Tsagakis K, et al. Treatment of infected thoracic aortic prosthetic grafts with the in situ preservation strategy: a review of its history, surgical technique, and results. Heart Lung Circ 2014; 23: 24-31.

3) Coselli JS, Köksoy C, LeMaire SA. Management of thoracic aortic graft infections. Ann Thorac Surg 1999; 67: 1990-3.

4) Czerny M, von Allmen R, Opfermann P, et al. Selfmade pericardial tube graft: a new surgical concept for treatment of graft infections after thoracic and abdominal aortic procedures. Ann Thorac Surg 2011; 92: $1657-62$.

5) Nakajima N, Masuda M, Ichinose M, et al. A new method for the treatment of graft infection in the thoracic aorta: in situ preservation. Ann Thorac Surg 1999; 67: 1994-6.

6) Teebken OE, Bisdas T, Assadian O, et al. Recommendations for reporting treatment of aortic graft infections. Eur J Vasc Endovasc Surg 2012; 43: 174-81.

7) Shiono N, Fujii T, Kawasaki M, et al. Frequency of detection of oral pathogenic bacteria in patients undergoing surgery for infectious endocarditis: is blood exposed to oral bacteria on a daily basis? J Clin Exp Cardiolog 2013; 4: 7.

8) Sasaki Y. The in vitro research of bacterial invasion of prosthetic vascular grafts: comparison of elastomersealed and gelatin-coated Dacron vascular grafts. Surg Today 2014; 44: 1542-7.

9) Bandyk DF. Vascular surgical site infection: risk factors and preventive measures. Semin Vasc Surg 2008; 21: 119-23.

10) Baddour LM, Bettmann MA, Bolger AF, et al. Nonvalvular cardiovascular device-related infections. Clin Infect Dis 2004; 38: 1128-30.

11) Takeuchi F, Sekizuka T, Yamashita A, et al. MePIC, metagenomic pathogen identification for clinical specimens. Jpn J Infect Dis 2014; 67: 62-5.

12) Hargrove WC, Edmunds LH. Management of infected thoracic aortic prosthetic grafts. Ann Thorac Surg 1984; 37: 72-7.

13) LeMaire SA, DiBardino DJ, Köksoy C, et al. Proximal aortic reoperations in patients with composite valve grafts. Ann Thorac Surg 2002; 74: S1777-80.

14) Nakajima $N$, Masuda $M$, Ichinose $M$, et al. A new method for the treatment of graft infection in the thoracic aorta: in situ preservation. Ann Thorac Surg 1999; 67: 1994-6.

15) Obdeijn MC, de Lange MY, Lichtendahl DH, et al. Vacuum-assisted closure in the treatment of poststernotomy mediastinitis. Ann Thorac Surg 1999; 68: 2358-60.

16) Fuchs U, Zittermann A, Stuettgen B, et al. Clinical outcome of patients with deep sternal wound infection managed by vacuum-assisted closure compared to conventional therapy with open packing: a retrospective analysis. Ann Thorac Surg 2005; 79: 526-31.

17) Akowuah E, Narayan P, Angelini G, et al. Management of prosthetic graft infection after surgery of the thoracic aorta: removal of the prosthetic graft is not necessary. J Thorac Cardiovasc Surg 2007; 134: 1051-2.

18) Saiki Y, Kawamoto S, Sai S, et al. An effective vacuumassisted closure treatment for mediastinitis with aortic arch replacement. Interact Cardiovasc Thorac Surg 2008; 7: 712-4.

19) Yasuura K, Okamoto H, Morita S, et al. Results of omental flap transposition for deep sternal wound infection after cardiovascular surgery. Ann Surg 1998; 227: 455-9.

20) Gustafsson R, Johnsson P, Algotsson L, et al. Vacuumassisted closure therapy guided by $\mathrm{C}$-reactive protein level in patients with deep sternal wound infection. $\mathbf{J}$ Thorac Cardiovasc Surg 2002; 123: 895-900. 